\title{
Comparative Studies on Cephalosporin C biosynthesis by Aspergillus and Acremonium Species
}

\author{
Zill-e-Huma Bilal $^{* 1}$, Adeela Yousaf ${ }^{1}$, Iffat Siddique ${ }^{2}$, Arusa $\mathrm{Aftab}^{3}$ \\ ${ }^{1}$ Institute of Agricultural Sciences, University of the Punjab, Lahore, Pakistan. \\ ${ }^{2}$ Botany \& Microbiology Department, College of science, King Saud University, Riyadh, KSA. \\ ${ }^{3}$ Department of Botany, Lahore College for Women University, Lahore, Pakistan.
}

\begin{abstract}
Three species of Aspergillus (A. niger, A. flavus, A. nidulans) and two species of Acremonium (A. furcatum and A. kiliense) were tested for their potential to biosynthesis of cephalosporin-C (CPC) in batch mode of cultivation before and after mutagenesis. The effects of different ingredients of the medium on CPC yield were thoroughly investigated. Results manifested that sucrose $30 \mathrm{mg} \mathrm{ml}^{-1}$, DL methionine $3 \mathrm{mg} \mathrm{mL}^{-1}$ and ammonium sulphate $7.5 \mathrm{mg} \mathrm{mL}^{-1}$ were most appropriate for maximum harvest of antibiotic. Mutants were achieved by exposing fungal cultures to $400 \mu \mathrm{g}$ $m L^{-1}$ of ethyl methane sulphonate (EMS) for 1 hour.
\end{abstract}

Keywords- Acremonium, Aspergillus, Cephalosporin C, Batch fermentation, Mutagenesis.

\section{INTRODUCTION}

Antibiotics are secondary metabolites produced by microorganisms, extremely important to the health of mankind. In the international market Cephalosporins have been proved as broad spectrum antibiotics belonging to $\beta$ lactams along with the penicillin but more resistant to $\beta$ lactamases than later (Kawahara et al., 2015). Similar to the penicillin $\mathrm{G}$, cephalosporin-C (CPC) is also produced during aerobic fermentations, acting as starting material for the manufacture of various semisynthetic cephalosporins by modifications on its side chains (Nigam et al., 2007). Different species of Acremonium have been investigated as potential source of cephalosporins. A number of reports are available on various aspects of CPC biosynthesis such as production in continuous mode or batch cultures, solid state or submerged fermentation and the use of free or immobilized cells of the microorganism etc. (Srivastva and Kundu, 1999; Cruz et al., 2001; Cruz et al., 2004). Much work is expended through strain improvement and introduction of modern fermentation technology to improve the production of this $\beta$-lactam antibiotic.
Optimization of media is useful to increase the production of antibiotics. $\mathrm{C} / \mathrm{N}$ ratio significantly effects the growth of the mold hence biosynthesis process is also under stress. Time of incubation is also an important factor as dry cell weights ascend promptly up to about 45 hours of fermentation, in comparison to total time of fermentation (Usher et al., 1988). Induction of mutation is commonly employed to increase the yield of metabolites. Chemical mutation is always preferred because of the ease in handling and avoiding the hazardous effects of the radiations. There are evidences of increase in the production of secondary metabolites after random mutation (Shafique et al., 2009, 2010).

\section{MATERIALS AND METHODS}

\section{Organism}

Five fungal species namely (Aspergillus niger FCBP 706, Aspergillus flavus FCBP 616, Aspergillus nidulans FCBP 166, Acremonium furcatum FCBP 409 and Acremonium kiliense FCBP 62) were obtained from First Fungal Culture Bank of Pakistan, Institute of Agricultural Sciences, University of the Punjab, Lahore Pakistan. The fungi were cultured and maintained on $2 \%$ malt extract agar (MEA) at $28{ }^{\circ} \mathrm{C}$ for 7 days. Storage temperature was adjusted at $4{ }^{\circ} \mathrm{C}$.

\section{Inocolum}

Surface growth from 7 days old slant was suspended in $5 \mathrm{ml}$ of sterile distilled water and was used to inoculate the seed medium.

Culture medium and conditions

The propagation of culture was carried out on seed medium containing $\left(\mathrm{g} \mathrm{L}^{-1}\right)$ Sucrose, 30; potassium dihydrogen orthophosphate, 1.5; magnesium sulphate, 0.3 ; and separately sterilized trace metal solution $15 \mathrm{~mL}$ (Nigam et al., 2007). The trace metal solution contained $\left(\mathrm{g} \mathrm{L}^{-1}\right)$ ferrous ammonium sulphate, 0.15; magnesium sulphate, 0.367; calcium chloride, 0.075; Zinc sulphate, 0.03; manganses sulphate, 0.03; and copper sulphate 0.008 . The culture was grown in the seed 
medium for 6-7 days at $28{ }^{\circ} \mathrm{C}$ in an orbital shaker set at 200 rpm.

Fermentation was carried out in shake flask at $28{ }^{\circ} \mathrm{C}$ for 144 hours on synthetic production medium containing $\left(\mathrm{g} \mathrm{L}^{-1}\right)$ Sucrose, 30; ammonium sulphate, 7.5; dipotassium hydrogen orthophosphate, 15.6; potassium dihydrogen orthophosphate 15.3; DL methionine 3.0; sodium sulphate, 1.7; oleic acid, 1.5. The $\mathrm{pH}$ of the medium was adjusted at 7.2 before sterilization. Concentrations of different media constituents were varied to study their effects on $\mathrm{CPC}$ production at shake flask level.

Five inorganic nitrogen sources (ammonium sulphate, ammonium nitrate, sodium nitrate, potassium nitrate and ammonium chloride) were chosen and their various concentrations were checked on CPC biosynthesis.

The effects of various concentrations (1-5 $\left.\mathrm{g} \mathrm{L}^{-1}\right)$ of Methionine on CPC were also studied, keeping other parameters constant. Concentration of sucrose $\left(20-40 \mathrm{~g} \mathrm{~L}^{-1}\right)$ was also varied in the synthetic medium to analyse its effect of CPC biosynthesis (Nitrogen constant, rpm 200, temperature $28{ }^{\circ} \mathrm{C}$ and time of fermentation 144 hours).

Analysis

Dry cell mass was calculated by filtration of the fermented broth through pre weighed whatman filter paper 01 and oven dried at $100{ }^{\circ} \mathrm{C}$ for 1 hour (Myers et al., 1997). Residual sugar was estimated after hydrolysis by 3, 5 Di Nitro Salicylic acid (DNS) method (Miller and Neuss, 1976). CPC produced in the fermented broth was estimated by adopting the method of Boxer and Everett (Boxer and Everett, 1959). Escherchia coli BCCP 406 were used as test organism to conduct the bioassay technique for CPC estimation.

\section{Strain improvement}

A suspension containing $3.5 \times 10^{6}$ conidia $\mathrm{mL}^{-1}$ prepared from one week old MEA plate was treated with $400 \mu \mathrm{g} \mathrm{mL}^{-1}$ ethyl methane sulphonate (EMS, Acros) for 30, 40, 50, .....80 minutes at $37{ }^{\circ} \mathrm{C}$ in a water bath. Then mixture was centrifuged for 20 minutes and washed 3 times with distilled water. The survivors were obtained by inoculating them on MEA plates with the addition of $0.1 \%$ triton X100 and $4 \mathrm{~g} \mathrm{~L}$

${ }^{1}$ L-Sorbose as colony restrictor. After achieving the mutants all the analysis were repeated to analyse their potential.

\section{Statistical analysis}

Data collected were subjected to analysis of variance (Steel and Torrie, 1980) followed by applying Duncan's Multiple rang (DMR) test at 5\% level of probability to compare treatment means.

\section{RESULTS AND DISCUSSION}

Microbes produce antibiotics as secondary metabolites and their biosynthesis is not associated with the growth of the producer i.e., their idiophase is not associated with the tropophase. Production of CPC has been reported to be associated with the morphological changes in the cell. It is well known that CPC is most actively synthesized at the time when hyphae are converted to arthrospores (Sohan et al., 1994). It has been observed that broth density varies with the time of fermentation. In early hours of fermentation the broth was watery but at became viscous after 50-60 hours (Mishra et al., 2005). Nigam et al., 2007 had also similar observation during fermentation process of CPC biosynthesis at shake flask as well as batch fermentation processes.

Effect of different concentrations of inorganic nitrogen sources on CPC biosynthesis by Aspergillus and Acremonium species

In addition to basic fermentation medium five inorganic nitrogen sources (ammonium sulphate, ammonium nitrate, potassium nitrate, sodium nitrate, and ammonium chloride) concentrations ranging from $7,7.5$ and $8 \mathrm{mg} \mathrm{mL}^{-1}$ were analysed for CPC biosynthesis. Spectrophotometric analyses of fermented broth showed that $A$. furcatum gave maximum CPC yield $(2.29 \mathrm{mg} / \mathrm{ml})$ at $7.5 \mathrm{mg} \mathrm{mL}^{-1}$ ammonium sulphate. The dry cell mass and sugar consumption on this concentration were 19.36 and $29.77 \mathrm{mg} \mathrm{mL}^{-1}$ respectively. Ammonium chloride and potassium nitrate followed by ammonium nitrate also gave good yields of CPC. The minimum yield of $\mathrm{CPC}$ was found with sodium nitrate as nitrogen source. (Fig. 1).

Variation in constituents of the media can play an important role in increasing the yield of CPC. The results from the present study manifest that nitrogen sources were very important precursors and readily available nutrients (Lee and Ryu, 1979). High nitrogen content was found to decrease the production of antibiotic. It might be due to interference in the process of differentiation of mycelium to swollen hyphal fragments and arthrospores during the production stage. Ammonium sulphate in comparison to other compounds added was observed to be the best inorganic nitrogen source for higher CPC biosynthesis. Nigam et al., 2007 also reported similar results. Kagliwal et al., 2009 analyzed nine different nitrogen sources for antibiotic production and maximum yield was achieved with (NH4)2 HPO4 and least with beef extract. Bussari et al., (2008) reported maximum production of antibiotic with ammonium oxalate.

Effect of different Sucrose concentrations on CPC biosynthesis by Aspergillus and Acremonium species 
Effects of different concentrations of carbon source (sucrose, 20-40 $\mathrm{mg} \mathrm{ml}^{-1}$ ) on CPC yield were studied in addition to the basic fermentation medium keeping all other parameters constant the results showed that with increase in sucrose concentration up to $30 \mathrm{mg} / \mathrm{ml}$, significantly higher antibiotic production was obtained, and then reduction in CPC yield was noted at higher sucrose concentration. (Fig. 2). Highest CPC yield $\left(2.583 \mathrm{mg} \mathrm{mL}^{-1}\right)$ was obtained by $A$. kiliense at $30 \mathrm{mg} \mathrm{mL}^{-1}$ sucrose concentration with dry cell mass and sugar consumption 22.22 and $29.888 \mathrm{mg} \mathrm{mL}^{-1}$ respectively. Concentration of sucrose is very crucial because at higher concentration of carbon source with a slow uptake rate, beneficial for the production (sucrose and high $\mathrm{C} / \mathrm{N}$ ratio), the yield of CPC declined. The investigation showed increased production of CPC by increasing the concentration of sucrose up to $30 \mathrm{mg} \mathrm{mL}^{-1}$ and then a decrease was observed. The reduction in CPC yield was due to accumulation of sucrose in broth at higher concentrations, inhibiting the synthesis of enzyme responsible for production of CPC. The results obtained are incompliance with findings of Nigam et al. 2007.

Effect of different DL-methionine concentrations on CPC biosynthesis by Aspergillus and Acremonium species

The DL-methionine has a stimulating effect on synthesis of CPC by playing a role in differentiation process. Different concentrations of DL-methionine in addition to the basic fermentation media were tested for enhancement of CPC production keeping all other fermentation parameters constant.

The results showed (Fig. 3) that CPC production increased with increase in the DL-methionine concentration up to 4.0 $\mathrm{mg} \mathrm{mL}^{-1}$ and thereafter decreased. (Fig. 3)

The results clearly showed an increased CPC yield $(2.342 \mathrm{mg}$ $\mathrm{mL}^{-1}$ ) at $3 \mathrm{mg} \mathrm{mL} 1$ of DL-methionine with A. kiliense. On this concentration the dry cell mass and sugar consumption are 39.46 and $29.835 \mathrm{mg} \mathrm{mL}^{-1}$ respectively.

DL-Methionine plays a significant role and reported to be active towards the syntheisis of CPC as lysine did for penicillin synthesis (Demain et al., 1963 and Demain and NewKrik, 1962). In the present study maximum CPC was produced at $3 \mathrm{mg} \mathrm{mL}^{-1}$ of DL-Methionine. The first step in the biosynthesis of antibiotic is the condensation of three amino acid precursors: $\alpha$-aminoadepate, L-cysteine and Lvaline to form ACV tripeptide. The $\alpha$-aminoadepate is generated from L-lysine by two sequential enzymatic steps. The first step involves a lysine-6-aminotransferase activity (LAT), considered to be one of the most rate limiting step for antibiotic biosynthesis. . The promising effect of lysine, valine, cystine and methionine on antibiotic production was also reported by Bussari et al., 2008 and Kagliwal et al., 2009. Enzymatic and genetic studies on methionine have revealed that it induces four of the enzymes of CPC biosynthesis at the level of transcription. It was also converted to cystine, on of the three precursors of CPC (Nigam et al., 2007).

\section{Visual observation of CPC Broth}

The fermentation broths for CPC production were monitored during fermentation process, and observed using a microscope (100×magnification). There was a notable change in broth characteristics. It exhibited high viscosity and appeared pale yellow in color. The clumps of mycelia were also observed, formed in the later stages of fermentation. The percentage of clumps was around 40-50\% of the sample. On microscopic observation, the biomass can be divided into two morphological forms, freely dispersed mycelial forms with 2-3 hyphal mycelia leading to hyphal loops in images and other clumped form which use these loops to define a structure.

\section{Effect of chemical mutation on CPC biosynthesis}

The effect of $1 \mathrm{hr}$ chemical mutation on CPC biosynthesis was screened as death rate, by A. niger, A. flavus, A. nidulans, $A$. kiliense and $A$. furcatum while keeping all fermentation conditions constant (Fig. 4). The results indicate that maximum CPC production (2.346 $\mathrm{mg} \mathrm{mL}^{-1}$ ) was achieved with $A$. furcatum with dry cell mass and sugar consumption 39.46 and $29.836 \mathrm{mg} \mathrm{mL}^{-1}$ respectively after mutation of 1hour. (Fig. 5).

The most important aim of the present study was improvement of the strain for enhanced biosynthesis of CPC by induction of chemical mutation, as mutation to increase the production of secondary metabolite has been reported by Demain, 1973. Result showed that as the exposure time increased the survival rate of fungi decreased. Maximum exposure time resulting least survivors (mutants) was 1 hour. Similar results were disclosed by Bhagwat and Duncum (1998); Cheema et al., (2002) and Lee et al. (2003). The results obtained for CPC production did not follow the pattern of the results to obtain the death rate, which may be due to insufficient mutation for required purpose.

\section{Estimation of CPC through Bioassay}

The antibacterial activity (Figs. $6 \& 7$ ) of CPC produced by Aspergillus and Acremonium species before and after mutation was confirmed by microbial growth inhibition test against Escherichia coli. The paper discs dipped in fermented broth were used for growth inhibition of test organism. The inhibition zones were measured after incubation of 24 hours. CPC produced by A. kiliense in fermented broth showed 
maximum antibacterial activity $(7.030 \mathrm{~mm}$ clear zone) against E. coli, as clear growth inhibition zone before mutation. While minimum inhibition zone $(1.05 \mathrm{~mm})$ was formed by $A$. flavus.

After mutation A. furcatum showed best inhibition zone $(6.015 \mathrm{~mm})$ against test organism. A. flavus here again showed minimum antibacterial activity by forming growth inhibition zone $0.55 \mathrm{~mm}$. The maximum inhibition zones formed by fermented broth of fungal species before and after mutation showed resemblance with the inhibition zone of $200 \mu \mathrm{g} / \mathrm{ml}$ Ceftriaxone.

The results of bioassay technique for CPC estimation has been depicted as inhibition of growth of $E$. coli by Sasaki et al., 2012. Against E. coli W (ATCC 9637). Nigam et al., 2007 conducted bioassay technique for CPC estimation using Alcaligenes faecalis (NCIM 2105) as test organism. Although Aspergillus niger was proved as potent CPC producing organism, but main hindrance is the biosynthesis of aflatoxin along with the CPC in the culture broth. Ultra purification techniques can be adopted for separation of aflatoxins from the antibiotics.

\section{CONCLUDING REMARKS}

Above investigations manifest that ammonium sulphate 7.5 $\mathrm{mg} \mathrm{mL}-1$ as inorganic nitrogen source, Sucrose $30 \mathrm{mg} \mathrm{mL}^{-1}$ and methionine at the concentration of $0.3 \mathrm{mg} \mathrm{mL}^{-1}$ were optimal for maximum yield of CPC. At higher (above optimal) the CPC biosynthesis was decreased. In the end it is concluded that optimization of media contents and induction of mutation can be used as efficient methods to increase biosynthesis of CPC at commercial level.

\section{REFERENCES}

[1] Bhagwat, B.; Duncan, E. J. Mutation breeding of Highgate (Musa acuminate AAA) for tolerance to Fusarium oxysporum f. sp. cubense using gamma irradiation. Euphy. 1998, 101(2): 143-150.

[2] Boxer, G. E.; Everett, P.M. Colorimetric determination of benzylpenicillin, colorimetric determination of total penicillins. Ana Chem. 1959, 21(6): 670-673.

[3] Bussari, B.; Saudagar, P. S.; Shaligram, N. S.; Survase, S. A.; Singhal, R. S. Production of cephamycin C by Streptomyces clavuligerus NT4 using solidstate fermentation. J indust microbiol \& biotech. 2008, 35: 49-58.

[4] Cheema, A. A.; Saleem, M. Y.; Awan, M. A. In vitro techniques for the selection of Basmati rice mutants better adapted to saline environments. In: Mutation, in vitro and Molecular Techniques for Environmentally
Sustainable Crop Improvement. Mauszynski, M. and Kasha, K. J., (ed.) IAEA, Vienna. 2002, 161-168.

[5] Cruz, A. J.G.; Almeida, Renate M.; Araujo, Maria Lucia G.C.; Giordano, Roberto C.; Hokka, Carlos O. Modeling and simulation of cephalosporin $\mathrm{C}$ production in a fed batch tower type bioreactor. Appl Biochem and Biotech. 2001, 93(1-3): 537-549.

[6] Cruz, A.J. G., Pan, T.; Giordano ,R.C.; Maria Lucia G. C. Araujo; M. L. G. C.; Hokka, C. O. Cephalosporin C production by immobilized Cephalosporium acremonium cells in a repeated batch tower bioreactor. Biotech and Bioeng. 2004, 85 (1): 96-102.

[7] Demain, L. A.; Newkirk, J. F.; Davis, G. E.; Harman, R. E. Nonbiological conversion of Cephalosporin $\mathrm{C}$ to a new antibiotic by sodium thiosulfate. Appl Microbiol. 1963, 11(1): 58-61.

[8] Demain, L. A. Mutation and the Production of Secondary Metabolites, Adv in Appl Microbiol. 1973, 11: 177-202.

[9] Kagliwal, L. D.; Survase, S. A.; Singhal, R. S. A novel medium for the production of cephamycin $\mathrm{C}$ by Nocardia lactamdurans using solid-state fermentation. Biores Technol. 2009, 100: 2600-2606.

[10] Kawahara, R.; Seto, K.; Taguchi, M.; Nakajima, C.; Kumeda, Y.; Suzuki, Y. Characterization of ThirdGeneration-Cephalosporin-Resistant Shiga ToxinProducing Strains of Escherichia coli O157:H7 in Japan. J Clin Microbiol. 2015, 53(9): 3035-3038

[11]Lee, K. M.; Ryu, D. D-Y. Studies on the Cephalosporin C Biosynthesis by Fermentation. Arch Pharml Res. 1979, 2(2): 79-83.

[12]Lee, I. S.; Kim, D. S.; Lim, Y. P.; Lee, K. S.; Song, H. S.; Lee, Y. I. Generation and performance evaluation of salt tolerant mutants in rice. Sab J Breed Gen. 2003, 35(2): 93-102.

[13] Miller, R. D.; Neuss, N. High performance liquid chromatography of natural products, separation of cephalosporin c derivatives and cephalosporin antibiotics; Isolation of cephalosporin $\mathrm{C}$ from fermentation broth. J antibio. 1976, 29 (9): 902-906.

[14] Mishra, P.; Srivastava, P.; Kundu, S. A comparative evaluation of oxygen mass transfer and broth viscosity using Cephalosporin-C production as a case strategy. W J Microbiol \& Biotech. 2005, 21: 525-530.

[15] Myers, D. K.; Lawlor, D. T. M.; Attifield, P. V. Influence of Invertase Activity and Glycerol synthesis and retention on fermentation of media with a higher sugar concentration by Sacchromyces cerevisiae. Appl Environ Microbiol. 1997, 63: 145-150. 
[16] Nigam, V. K.; Verma, R.; Kumar, A.; Kundu, S.; Ghosh, P. Influence of medium constituents on the biosynthesis of Cephalosporin-C. Elect J Biotech. 2007, 10 (2): 230-239.

[17] Sasaki Y.; Usui M.; Murakami M.; Haruna M.; Kojima A.; Asai T.; Yamada Y. Antimicrobial resistance in Shiga toxin-producing Escherichia coli O157 and O26 isolates from beef cattle. Jpn J Infect Dis. 2012, 65:117-121.

[18] Shafique, S.; Bajwa, R.; Shafique, S. Mutation of Alternaria tenuissima GCBP-252 for hyper active $\alpha$ amylase. Ind J Exp Biol. 2009. 47: 591-596.

[19] Shafique, S.; Bajwa, R.; Shafique, S. Mutagenesis and genetic characterization of amylolytic Aspergillus niger. N P RES. 2010, 24 (12): 1104-1114.
[20] Sohn, Y-S.; Lee, K-C.; Koh, Y-H.; Gil, G-H. Changes in Cellular Fatty Acid Composition of Cephalosporium acremonium during Cephalosporin C Production. Appl Enviro Microbiol. 1994, 60(3): 947-952.

[21] Steel, R. D. G.; Torrie J. H. Principles and Procedures of Statistics. A Biometrical Approach. $2^{\text {nd }}$ edition. Mc Graw Hill Book Co. Inc. New Y York, USA. 1980.

[22] Srivastava, P.; Kundu, S. Studies on cephalosporin C production in an air lift reactor using different growth modes of Cephalosporium acremonium. Pro Biochem. 1999, 34(4): 329-333.

[23] Usher, J. J.; Lewis, M.; Hughes, W. D.; Compton, B. J. Development of the cephalosporin $\mathrm{C}$ fermentation taking into account the instability of cephalosporin $\mathrm{C}$. Biotech Letters. 1988, 10 (8): 543-548. 

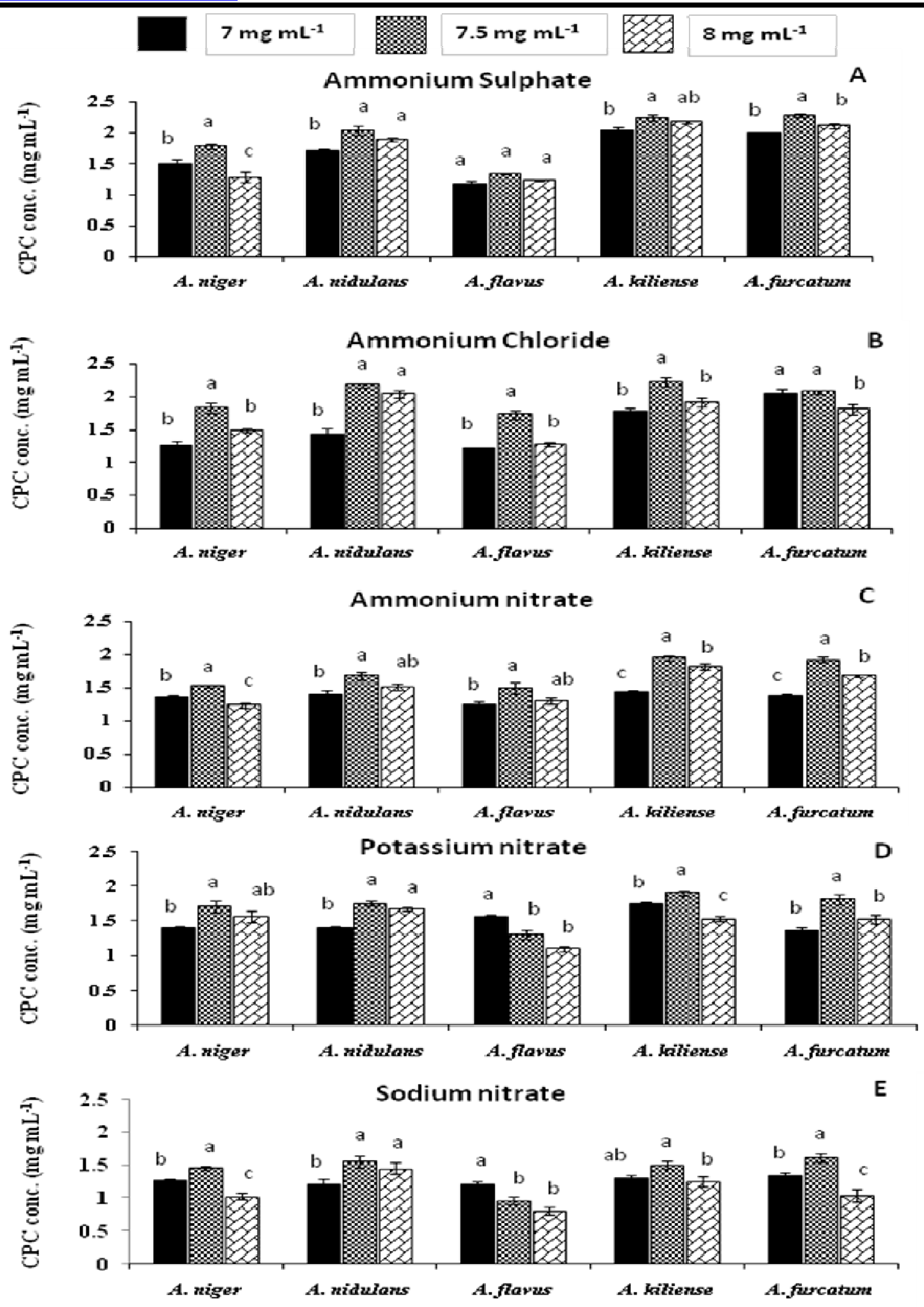

Fig.1: Effect of different concentrations of Inorganic salts on the biosynthesis of Cephalosporin C by different species of Aspergillus and Acremonium. 


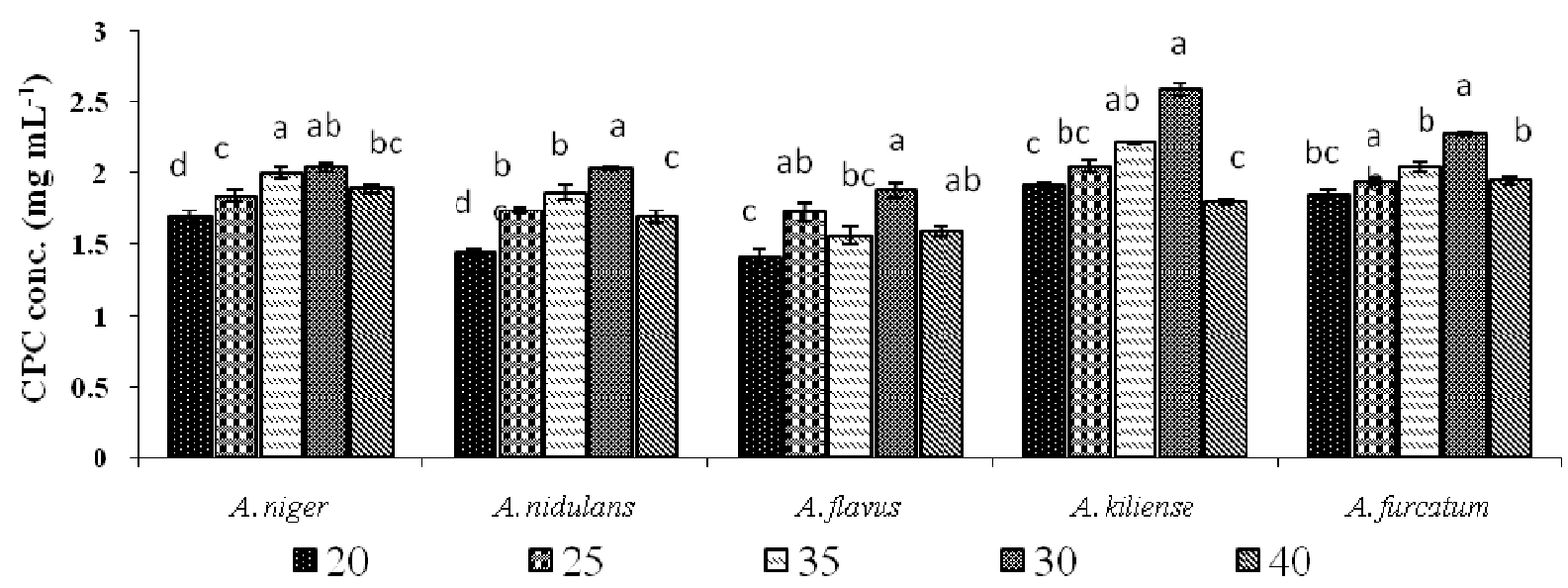

Fig.2: Effect of different Sucrose concentrations on CPC biosynthesis by different species of Aspergillus and Acremonium.

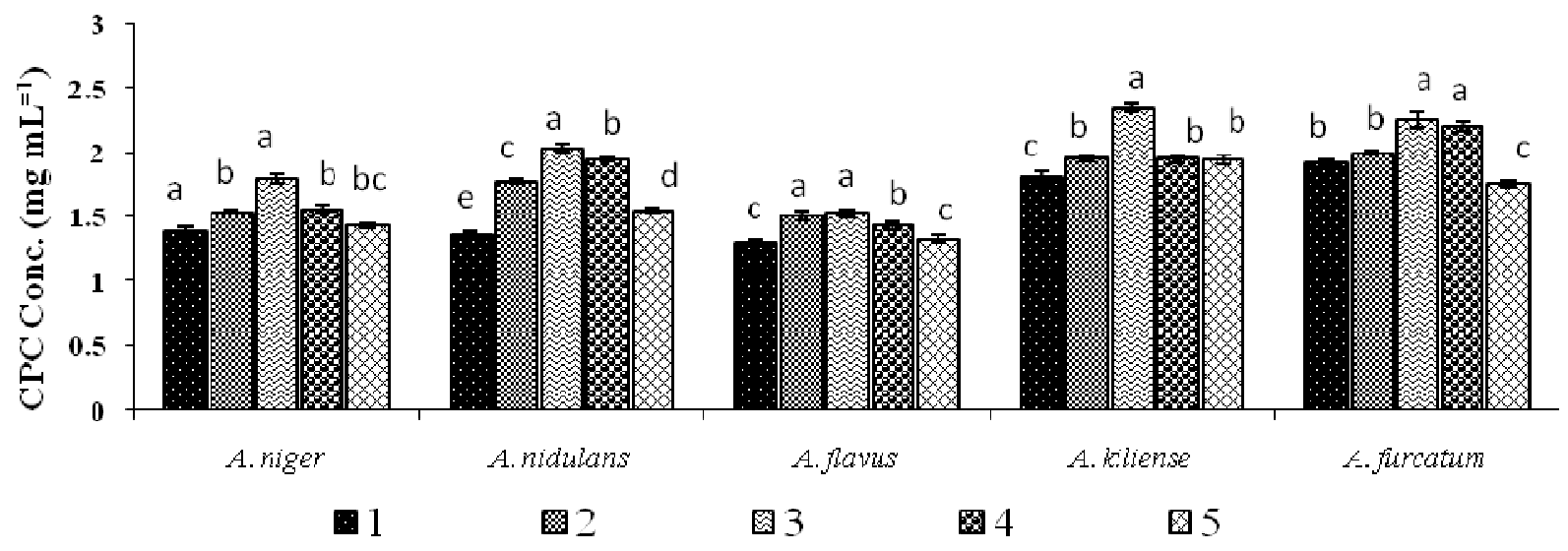

Fig.3: Effect of different DL-methionine concentrations on CPC biosynthesis by different species of Aspergillus and Acremonium

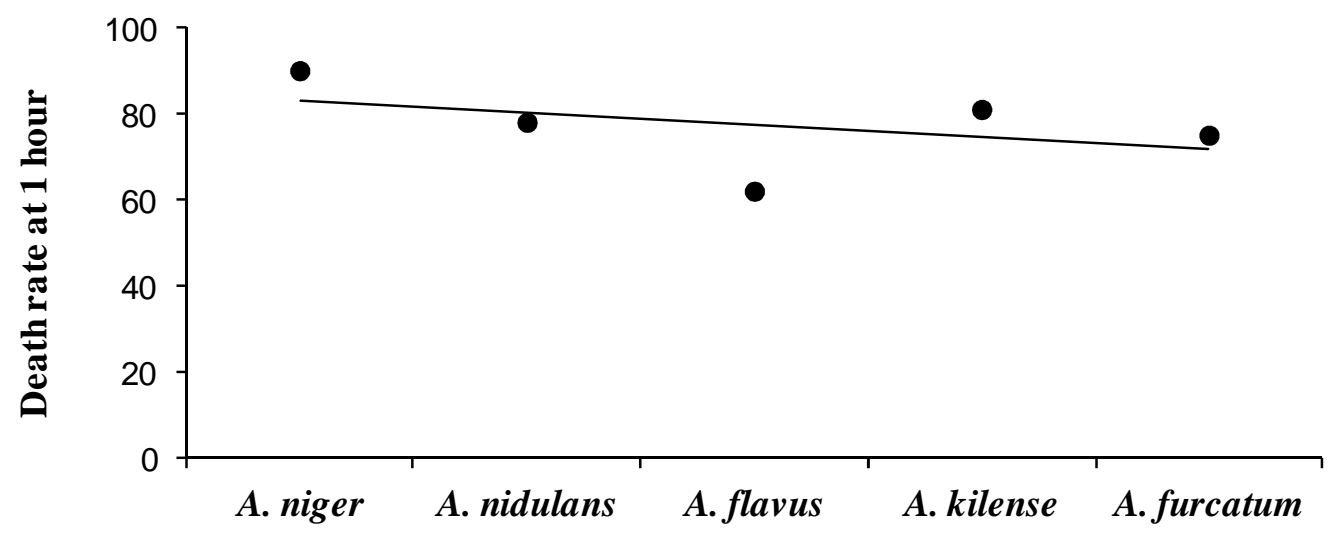

Fig.4: Effect of chemical mutation on fungal species after 1hour 


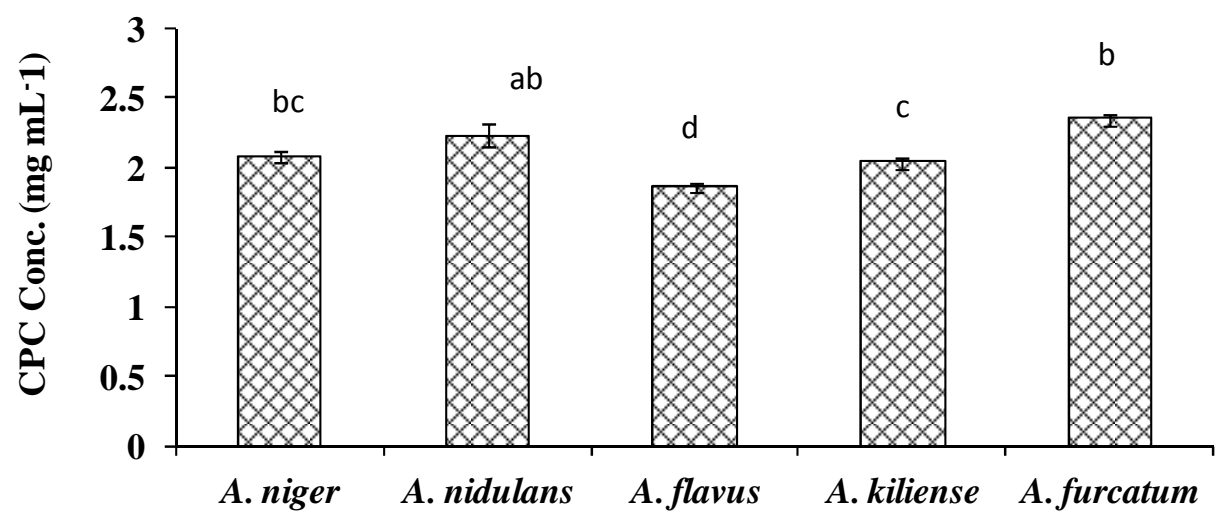

Fig.5: Effect chemical mutation on CPC biosynthesis by Aspergillus and Acremonium spp.

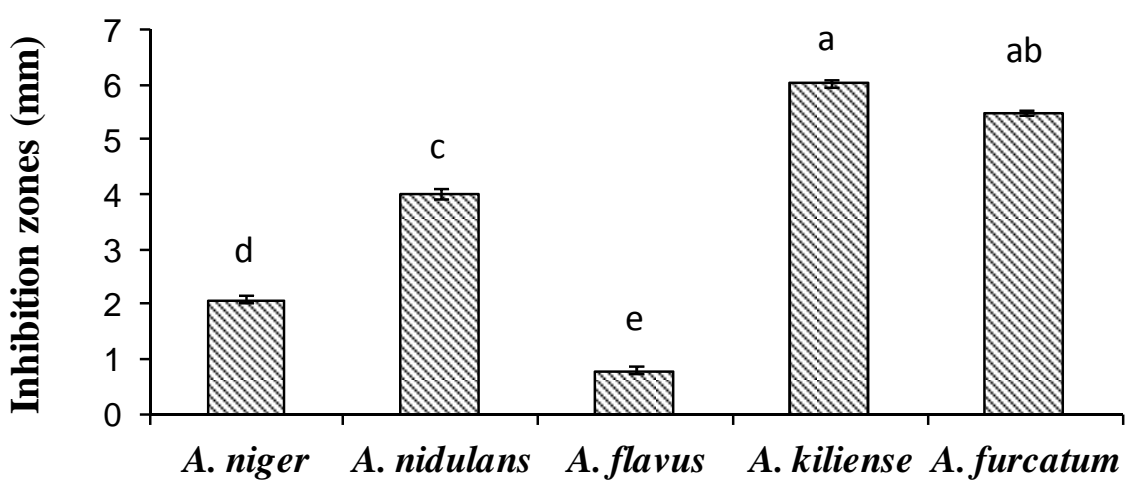

Fig.6: Bioassay estimation for CPC biosynthesis before chemical mutation

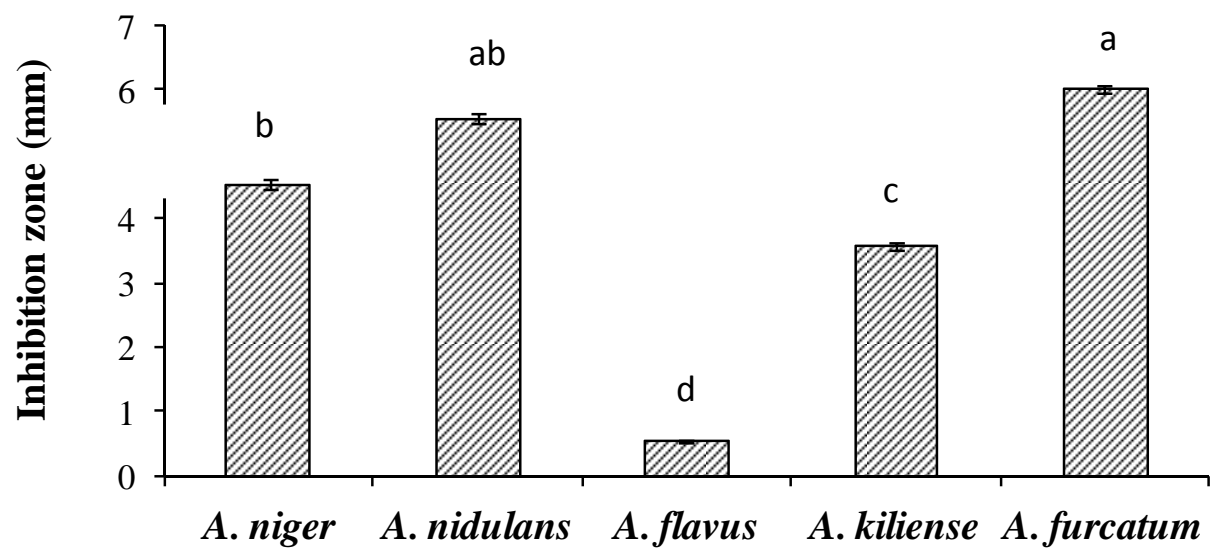

Fig.7: Bioassay estimation for CPC biosynthesis after chemical mutation 